\title{
Diaphragmatic motility assessment in COPD exacerbation, early detection of Non-Invasive Mechanical Ventilation failure: a pilot study
}

\author{
Fabio Giuliano Numis ${ }^{1 *}$, Lucia Morelli ${ }^{1}$, Giorgio Bosso ${ }^{1}$, Mario Masarone ${ }^{2}$, Sara Cocozza ${ }^{1}$, Anita Costanzo ${ }^{1}$ \\ Fernando Schiraldi ${ }^{\top}$
}

From 7th WINFOCUS Italian Congress on Ultrasound in Emergency, Anaesthesiology and Critical Care Lodi, Italy. 26-29 March 2014

\section{Background}

Patients with respiratory failure due to Chronic Obstructive Pulmonary Disease (COPD) have decreased diaphragmatic mobility [1]. Non Invasive Mechanical Ventilation (NIMV) is a cornerstone in COPD exacerbation therapy. The availability of early predictors of NIMV failure may be helpful to guide decision-making. Only $\mathrm{pH}$, respiratory rate and $\mathrm{PaO} 2 / \mathrm{FiO} 2$ have been considered predictors of response to NIMV [2]. Ultrasonographic (US) assessment of diaphragmatic kinetic is a fast, reliable and reproducible method [3], but its predictive value on NIMV success is not known.

\section{Objective}

Primary endpoint was to evaluate if the diaphragmatic excursion measurement was able to predict a longer weaning time. Secondary endpoint was to find out a cut-off value of diaphragmatic excursion and a weaning time interval able to predict worst outcome.

\section{Methods}

Fifty-two (39 males, aged $71 \pm 7$ years) Caucasian patients with COPD exacerbation treated with NIMV were enrolled. Diaphragm motility was assessed by ultrasonography before starting ventilation at 6 and 24 hours and at the weaning from NIMV. The diaphragmatic excursion (centimeters); the inspiratory and expiratory times (seconds); the inspiration and expiration velocity $(\mathrm{cm} / \mathrm{sec})$, the breathing period (seconds), the diaphragm motion time (seconds) and the diaphragm resting time (seconds) were evaluated.

* Correspondence: fabionumis@libero.it

${ }^{1}$ UOC Pronto Soccorso-Medicina d'Urgenza, Ospedale S. Paolo, Napoli, Italy

Full list of author information is available at the end of the article

\section{Results}

Forty-five patients completed the study. The mean time on NIMV was $4.11 \pm 1.07$ days, with a total time of ventilation of $32.6 \pm 86$ hours. All the ultrasound diaphragm motility parameters, except for inspiration and expiration velocity, significantly improved at the weaning. Diaphragm excursion at the baseline was significantly correlated with $\mathrm{pH}(\mathrm{r}=0.458 ; \mathrm{p}=0.002), \mathrm{PaO}_{2} / \mathrm{FiO}_{2}(\mathrm{r}=0.567 ; \mathrm{p}<0.001)$, and weaning time $(\mathrm{r}=0.774 ; \mathrm{p}<0.0001)$. In a multiple linear regression analysis only diaphragm excursion was significantly associated with longer weaning time (coefficient of estimated model -9.247; Standard Error 3.101; $\mathrm{p}=0.003$ ). ROC curve with weaning time longer than 36 hours was considered as positive state. The AUC value was 0.912 (Standard Error 0.015, $\mathrm{p}<0.001$ ). The higher sensitivity rate $(100 \%)$ was achieved with a specificity rate of $86.7 \%$ and a cut-off value of $3.165 \mathrm{~cm}$, therefore patients with an excursion lower than $3.165 \mathrm{~cm}$ should be weaned after at least 36 hours, while patients with an excursion higher than $3.165 \mathrm{~cm}$ could be weaned within 36 hours.

\section{Conclusion}

US measurements of diaphragmatic performance may have a role in the early evaluation of exacerbation of COPD and in predicting the response to NIMV therapy, it should be included as a routine test in patients presenting to ED with ECOPD.

\section{Authors' details \\ 'UOC Pronto Soccorso-Medicina d'Urgenza, Ospedale S. Paolo, Napoli, Italy. ${ }^{2}$ Dipartimento di Medicina Interna ed Epatologia, Università di Salerno, Italy.}

Published: 27 August 2014 


\section{References}

1. Yamaguti WP, Paulin E, Shibao S, et al: Air trapping: the major factor limiting diaphragm mobility in chronic obstructive pulmonary disease patients. Respirology 2008, 13:138-144.

2. Ram SFF, Picot J, Lightowler J, Wedzicha AJ, et al: Non-invasive positive pressure ventilation for treatment of respiratory failure due to exacerbations of chronic obstructive pulmonary disease. Cochrane Database Syst Rev 2004, 3(1):CD004104.

3. Testa A, Soldati G, Giannuzzi R, et al: Ultrasound M-mode Assessment of diaphragmatic kinetics by anterior transverse scanning in healthy subjects. Ultrasound in Med \& Biol 2011, 37:44-52.

doi:10.1186/2036-7902-6-S2-A6

Cite this article as: Numis et al.: Diaphragmatic motility assessment in COPD exacerbation, early detection of Non-Invasive Mechanical

Ventilation failure: a pilot study. Critical Ultrasound Journal 2014

6(Suppl 2):A6.

\section{Submit your manuscript to a SpringerOpen ${ }^{\circ}$ journal and benefit from:}

- Convenient online submission

- Rigorous peer review

- Immediate publication on acceptance

- Open access: articles freely available online

- High visibility within the field

- Retaining the copyright to your article

Submit your next manuscript at $>$ springeropen.com 